\title{
Top-Down Analysis of Forest Structure and Biogeochemistry across Hawaiian Landscapes ${ }^{1}$
}

\author{
Peter M. Vitousek, ${ }^{2,6}$ Michael A. Tweiten, ${ }^{3}$ Fames Kellner, ${ }^{4}$ Sara C. Hotchkiss, ${ }^{3}$ \\ Oliver A. Chadwick, ${ }^{5}$ and Gregory P. Asner ${ }^{4}$
}

\begin{abstract}
Technical and analytical improvements in aircraft-based remote sensing allow synoptic measurements of structural and chemical properties of vegetation across whole landscapes. We used the Carnegie Airborne Observatory, which includes waveform light detection and ranging (LiDAR) and high-fidelity imaging spectroscopy, to evaluate the landscapes surrounding four well-studied sites on a substrate age gradient across the Hawaiian Islands. The airborne measurements yielded variations in ground topography, canopy height, and canopy nitrogen $(\mathrm{N})$ concentration more accurately than they could have been obtained by any reasonable intensity of ground-based sampling. We detected spatial variation in ecosystem properties associated with the properties of different species, including differences in canopy $\mathrm{N}$ concentrations associated with the native species Metrosideros polymorpha and Acacia koa, and differences brought about by invasions of the biological $\mathrm{N}$ fixer Morella faya. Structural and chemical differences associated with exotic tree plantations and with dominance of forest patches by the native mat-forming fern Dicranopteris linearis also could be analyzed straightforwardly. This approach provides a powerful tool for ecologists seeking to expand from plot-based measurements to landscape-level analyses.
\end{abstract}

Substantial effort has gone into determining and analyzing ecosystem properties and processes on a long substrate age gradient (LSAG) across the Hawaiian Archipelago (Crews et al. 1995, Kitayama and Mueller-

\footnotetext{
${ }^{1}$ Research supported by NSF grants DEB-0716852, -0715593,-0717382, and -0715674; NASA Terrestrial Ecology Program-Biodiversity grant NNG-06-GI-87G; and the Carnegie Institution. The Carnegie Airborne Observatory is made possible by the W. M. Keck Foundation and William Hearst III. Manuscript accepted 1 September 2009.

2 Department of Biology, Stanford University, Stanford, California 94305 (e-mail: vitousek@stanford.edu).

${ }^{3}$ Department of Botany, Birge Hall, University of Wisconsin, Madison, Wisconsin 53706.

${ }^{4}$ Department of Global Ecology, Carnegie Institution of Washington, Stanford, California 94305.

${ }^{5}$ Department of Geography, University of California, Santa Barbara, California 93106.

${ }^{6}$ Corresponding author.
}

Pacific Science (2010), vol. 64, no. 3:359-366

doi: 10.2984/64.3.359

(C) 2010 by University of Hawai'i Press

All rights reserved
Dombois 1995, Riley and Vitousek 1995, Chadwick et al. 1999, Herbert and Fownes 1999, Vitousek 2004), as a model for understanding long-term soil and ecosystem development. As with other gradient-based studies, the LSAG research has focused on particular sites that were selected to represent each substrate age. This focus on particular sites is useful because sources of variation other than substrate age (topography, human disturbance, biological invasion) can be controlled through careful site selection; moreover, where long-term experiments (Vitousek and Farrington 1997, Harrington et al. 2001) or expensive or repeated measurements (Hobbie and Vitousek 2000, Wiegand et al. 2005) are carried out, it may also be the only practical approach. However, this site-based approach does not account for spatial variation in ecosystem properties on landscapes, whether that variation arises from systematic changes in landscapes that occur as a consequence of substrate age or from other processes.

Remote sensing offers a means for evaluating landscapes synoptically, rather than site 
by site. However, until recently most remote sensing methods have been insensitive to any but extreme variations in the structure and biogeochemistry of ecosystems. Recent advances in light detection and ranging (LiDAR) (Lefksy et al. 2002) and in high spectral and spatial resolution imaging spectroscopy (High-Fidelity Imaging Spectroscopy, or HiFIS) (Smith et al. 2002, Ustin et al. 2004) have made it possible to measure certain structural and chemical properties of ecosystems across landscapes. In previous studies, we have used LiDAR and HiFIS separately to evaluate the landscape-level influence of biological invasions on the threedimensional structure and canopy nitrogen (N) concentrations of Hawaiian forests (Asner and Vitousek 2005, Asner et al. 2008), and of erosion/topography on phosphorus biogeochemistry in the oldest landscape on the gradient (Porder et al. 2005a).

An earlier study (Vitousek et al. 2009) used LiDAR and HiFIS in combination to evaluate aspects of forest structure and biogeochemistry on the landscape level in four sites across the Hawaiian substrate age gradient. That study demonstrated that although the same patterns in canopy height (taller in the two younger sites) and canopy $\mathrm{N}$ concentrations (higher in the two intermediateaged sites) occur on the landscape scale as were observed in ground-based research on the focal sites in each landscape, the longterm research sites were biased toward areas with taller-than-average canopies within each landscape, particularly on the two older substrates. That study also demonstrated that stratification of landscapes into cover classes defined by the influence of invasion, erosion/topography, human disturbance, and other processes accounts for a substantial proportion of the variation in canopy height and $\mathrm{N}$ concentration within some of the landscapes.

In this paper, we use the same LiDAR and HiFIS information together with groundbased sampling to understand aspects of forest structure and biogeochemistry in $2 \mathrm{~km}$ by $2 \mathrm{~km}$ regions around each of the four agegradient sites. The earlier paper focused on landscape-level changes in ecosystem proper- ties across the substrate age gradient, but here we concentrate on using the imagery to understand sources of variation in ecosystem structure and composition within each region. We thereby seek to place each of the long-term research sites into the context of the landscape that encompasses it.

\section{MATERIALS AND METHODS}

\section{Study Sites and Landscapes}

The 4-million-year LSAG across the Hawaiian Archipelago consists of a series of sites that are matched in elevation $(1,200 \mathrm{~m})$, annual precipitation $(2,500 \mathrm{~mm})$, topography (constructional surface of shield volcanoes), vegetation $(>80 \%$ basal area is the native tree Metrosideros polymorpha Gaud), and to the extent possible disturbance history (none has been cleared by people). The gradient is described in detail in Vitousek (2004), and the peculiarities of particular sites are described in supplemental material accessible at http://www.stanford.edu/group/Vitousek/ princetonbook.html. Here we focus on $2 \mathrm{~km}$ by $2 \mathrm{~km}$ landscapes surrounding four of the focal sites on the LSAG: the 0.3-thousandyr-old (kyr) Thurston, 20 kyr Laupāhoehoe, 150 kyr Kohala, and 4,100 kyr Kōke'e sites. The first three sites are on the island of Hawai' $i$; the last is on the island of Kaua' $i$.

\section{Remote Sensing}

Methods for the remote sensing analyses are described in Vitousek et al. (2009). Briefly, we used the Carnegie Airborne Observatory (CAO), a system designed to determine chemical and structural properties of vegetation from the air (http://cao.stanford.edu) (Asner et al. 2007). The CAO combines three instrument subsystems into a single airborne package: (1) High-Fidelity Imaging Spectrometer (HiFIS), here the Airborne Visible and Infrared Imaging Spectrometer (AVIRIS) (Green et al. 1998); (2) Waveform Light Detection and Ranging (LiDAR) scanner; and (3) Global Positioning System-Inertial Measurement Unit (GPS-IMU). We used methods described by Asner et al. (2007) to match 
HiFIS and LiDAR data in three-dimensional (3-D) space. The system was operated from January to February 2007 at an altitude averaging $3.0 \mathrm{~km}$ above ground level, thus providing spectroscopic measurements at $3.0 \mathrm{~m}$ spatial resolution and LiDAR spot spacing (postings) of $1.0-1.5 \mathrm{~m}$, depending upon the site. The GPS-IMU data were combined with the laser range data to determine the 3-D location of the laser returns. From the LiDAR point cloud data, a physically based model was used to estimate top-of-canopy and ground digital elevation models (DEM) using REALM (Optech Inc., Toronto, Canada) and Terrascan/Terramatch (Terrasolid Ltd., Jyväskylä, Finland) software packages. Vegetation height was then calculated as the difference between the top-of-canopy and ground DEM.

The HiFIS data were converted to atsensor radiances by applying radiometric corrections developed during sensor calibration in the laboratory. Apparent surface reflectance was then derived from the radiance data using an automated atmospheric correction model, ACORN 5LiBatch (Imspec LLC, Palmdale, California), with settings described by Asner et al. (2008). Upper-canopy leaf N concentration was estimated from the HiFIS data using the visible $(450-690 \mathrm{~nm})$ and the shortwave-infrared (1,500-2,400 nm) wavelength regions, as described by Asner and Vitousek (2005).

\section{Field Observations}

The processed images resulting from LiDAR and HiFIS acquisitions provided a synoptic view of the topography, canopy height, and upper-canopy $\mathrm{N}$ concentration across $2 \mathrm{~km}$ by $2 \mathrm{~km}$ landscapes centered on each of the focal sites. Formal validation of the accuracy of these products was carried out separately (see Asner and Vitousek [2005] for canopy $\mathrm{N}$, Asner et al. [2008, 2009] for vegetation height); here, we sought to use ground-based observations to understand sources of the spatial variation detected by remote sensing.

Our field sampling was primarily descriptive; we printed the topographic, tree height, and canopy $\mathrm{N}$ images from each area with an overlay of GPS coordinates and selected sample points in advance. For these sample points, we sought representation of both frequent and unusual combinations of remotely detected topography, canopy height, and canopy $\mathrm{N}$ within each landscape. We took the images into the field and used GPS to locate the preselected points. Additional sample points were selected in the field when conditions not encompassed by the preselected points were encountered. In most cases, we knew what to expect from the imagery; for example, very tall homogeneous patches of forest on a consistent slope likely represent plantations of exotic trees, and our field observations confirmed those expectations. In other cases we did not know what to expect when we reached the selected points, and the ground observations were essential to understanding the remote observations.

At each point, we recorded canopy characteristics (dominant canopy and understory species, visual estimates of structure), obtained GPS coordinates, and obtained and archived two digital photographs, one taken vertically that showed the canopy and one taken horizontally showing the understory. This approach allowed us to walk through the sites both virtually (observing the images) and literally (with the images in hand); it provides a powerful way to identify and evaluate landscape-level variation in forest ecosystems. Both the remote images and the groundbased information and photographs are accessible at http://www.stanford.edu/group/ Vitousek/lsaglandscape.htm. We encourage readers to scroll through the images and photographs and develop their own sense for these landscapes.

\section{Patterns in Topography and Forest Canopies}

The LiDAR-derived topographies of the 2 $\mathrm{km}$ by $2 \mathrm{~km}$ landscapes across the substrate age gradient are illustrated in Plates I-IV; the same information is presented in Vitousek et al. (2009), but the figures are organized and used differently there, and additional information is provided. The topographic images provide remarkable resolution, even under forest canopies, and in some cases they enabled us 
to identify and explain topographic features that we had not interpreted correctly in 20$25 \mathrm{yr}$ of fieldwork in and around these sites.

Topography is an important source of variation in forest ecosystems; fluvial erosion and deposition influence nutrient availability and can cause differences in foliar chemistry among sites (Porder et al. 2005a,b), and topography can shelter stands from wind disturbance, thereby affecting their structure and chemistry. Also, steep topography can interfere with our analyses of both tree height and canopy $\mathrm{N}$ : the former because the uphill and downhill sides of a given tree yield different returns to the LiDAR ( $\mathrm{Su}$ and Bork 2006); the latter because steep slopes create shadows that make it difficult to derive biochemically meaningful spectra (Roberts et al. 1993, Kupiec and Curran 1995). Accordingly, we classified steep slopes ( $>20$ degrees) as erosionally or volcanically derived but then masked them out of further analyses.

We then evaluated canopy heights from LiDAR and $\mathrm{N}$ concentrations from HiFIS (Plates I-IV) across the landscapes. In combination with topography, and with our ground-based observations of a number of points in each landscape, we defined areas within each $2 \mathrm{~km}$ by $2 \mathrm{~km}$ landscape that represented little-invaded native forest growing on constructional geomorphic surfaces, and areas that were influenced substantially by biological invasions ("substantially" defined by areas in which invaders influenced remotely detected canopy properties); fluvial erosion or deposition and steep or recent volcanic topography (from the image of topography); human disturbance or land use (based on remotely detected canopy properties supplemented by ground observations); steep climatic gradients within a landscape; or other sources of variation (Plates I-IV).

\section{RESULTS AND DISCUSSION}

\section{Thurston Landscape (0.3 kyr)}

The topography surrounding the youngest region on the LSAG is constructional; all of the relief visible in the topographic image (Plate I) is volcanic in origin. Across most of this landscape, the substrate is pāhoehoe lava overlain with cinder. The major topographic features are the wall and floor of Kilauea Iki Crater to the west of the focal site (points 14 and 15; the point numbers are shown in the upper left section of each plate and online as discussed earlier), and a nearby series of pits that resulted from the collapse of portions of the ceiling of the large underlying Thurston Lava Tube. Away from the 50-yr-old lava lake in Kîlauea Iki Crater, most of the area is covered by forests of intermediate height (10-20 m) (Plate I); shorter canopies occur in active and abandoned pastures in the northern part of the image $(34,37)$, in smaller areas of stand-level dieback north and east of the focal site $(6,8)$, and in areas with shallow soils that ground observations show to be codominated by the mat-forming fern Dicranopteris linearis Underw. in the southwestern part of the image (18).

The major source of variation in canopy $\mathrm{N}$ across this landscape (Plate I) is biological invasion by the actinorrhizal N-fixing tree Morella (Myrica) faya (Aiton) Wilbur (points 7, 21, 32, and others). Canopy $\mathrm{N}$ levels are increased in invaded stands, but canopy heights are similar and have the same level of variability as in intact stands (Plate I). A planted stand of the native N-fixer Acacia koa (point 35 ) also created an area of high canopy $\mathrm{N}$. Overall, biological invasion, human land clearing, and volcanic activity affect substantial fractions of the Thurston landscape (Plate I).

\section{Laupāhoeboe Landscape (20 kyr)}

The focal site for the second-youngest landscape is located on small interfluve in deep volcanic ash soils (Plate II). The area to the south and east of this site is covered by a 5,000-yr-old Mauna Kea lava flow (Wolfe and Morris 1996). Most of the 'a' $\bar{a}$ lava flow surface is little dissected by erosion; its topography largely reflects lava pressure ridges and flow channels. However, the portion of this flow within $\sim 300 \mathrm{~m}$ of the focal site is mantled with tephra tens of centimeters thick, as can be seen from the subdued flow topography there (Plate II) and as is confirmed from 
ground observations. We wonder if in fact there are two flows here, with an older one closer to the focal site partially overridden by the 5,000-yr-old flow farther to the south and east, or alternatively if the portion of the flow nearest the focal site represents an early portion of the flow that was covered by later tephra from the same eruptive episode. Within the northwesterly portion of the landscape that is underlain by deeper ash soils, the drainage network is fine but shallow, with little more than $5 \mathrm{~m}$ of local relief. Older landscapes have deeper but sparser drainage networks, as discussed in the next sections.

Tree heights within the Laupāhoehoe landscape vary substantially, with larger trees downslope to the northeast (points 22-26) (Plate II, upper right). The larger trees in Laupāhoehoe are substantially taller than those at Thurston $(>25 \mathrm{~m}$ versus $<20 \mathrm{~m})$, and their crowns are broader as well; individual trees stand out in the Laupāhoehoe canopy-height image (for example, a tall Acacia koa A. Gray at 32), but they rarely are distinguishable at Thurston (or the older sites). At the same time, there are extensive areas of shorter canopies in the Laupāhoehoe landscape-more so than within native forest at Thurston. The shorter areas reflect human land use (ongoing koa logging in the adjacent, partially cleared Waipunalei aьириа' $a[4,5]$ and some past logging in the upper-elevation portion of Laupāhoehoe itself), a few small hollows and bogs (20), and, most important, the legacy of canopy dieback (MuellerDombois 1986), especially on the deep volcanic ash substrates. Ground observations reveal that much of the dieback area has a canopy of tall Cibotium spp. tree ferns, with standing dead trees $(7,35)$.

Canopy $\mathrm{N}$ concentrations also vary across the Laupāhoehoe landscape (Plate II), with many values in excess of those observed in the Thurston landscape. In part high $\mathrm{N}$ concentrations result from the presence of Acacia $k o a$, an N-fixer, within the Laupāhoehoe forest; tall individuals of Metrosideros and Acacia are readily distinguishable in the imagery based on their $\mathrm{N}$ signature $(22,24)$, as ground observations here quickly confirmed. However, even Metrosideros is substantially higher in $\mathrm{N}$ at Laupāhoehoe than at Thurston, as was observed earlier in ground-based sampling (Vitousek et al. 1995). The $\mathrm{N}$ image demonstrates that Acacia reaches its distributional limit within the Laupāhoehoe image, as evidenced by the arc of higher- $\mathrm{N}$ canopies that passes through points 29,30 , and 41 ; it is absent from the slightly wetter forests in the southeastern portion of the image and more abundant in the drier (and more disturbed) forests to the northwest. Acacia also responds strongly to soil scarification, contributing to its abundance along the road $(28,41)$ and the Laupāhoehoe-Waipunalei boundary fence line (5) as well as in logged areas.

\section{Kobala Landscape (150 kyr)}

Kohala is a smaller mountain than Mauna Kea, and the focal LSAG site is located just $400 \mathrm{~m}$ south-southeast of a block fault (point 10) that bounds a central graben near the mountain summit (Plate III). The topographic image demonstrates that volcanic features are surprisingly prominent in this landscape, for a region that has not experienced local volcanism for $\sim 150 \mathrm{kyr}$. The landscape contains several cinder cones that erupted 150-220 kyr ago and several trachyte lava flows (including a large one westnorthwest of 53) representative of this later (alkalic) stage of Hawaiian volcanism. The focal site itself is on an interfluve underlain by alkalic ' $a$ ' $\bar{a}$ lava; the local drainage network is coarser and deeper than that in the Laupāhoehoe landscape.

Canopy heights are relatively short and extremely variable across the Kohala landscape (Plate III), reflecting the influence of a steep rainfall gradient and multiple additional controlling factors. The southern one-third of the landscape has been cleared and converted to pasture $(15,32,33,53)$; trees remain in that landscape primarily in and near gullies. Several species of exotic trees were planted in the 1920s and 1930s at and near the upper margin of the pasture; some of these (Eucalyptus spp. and Cryptomeria japonica (L. f.) D. Don in particular) $(14,18,31,35)$ represent the tallest trees in this and the older Kōke'e landscapes. 
The area beyond the block fault northnortheast of the focal site (43-52) receives substantially more rainfall than the LSAG site, and it supports areas of short-canopy Metrosideros forest interspersed with Sphagnum palustre L. and Metrosideros-covered bogs with occasional patches of taller Metrosideros $(43,45)$. Finally, the region to the westnorthwest of the focal site is similar to it climatically, but canopies are short and codominated by the mat-forming fern Dicranopteris linearis. Fern dominance reflects dieback of the Metrosideros overstory in some portions of the area, with standing dead trees over a nearly monospecific layer of fern $(28,36$, 40 ); in other areas, the Dicranopteris is climbing into what appears to be a growing, postdisturbance stand of Metrosideros $(27,41)$.

Canopy $\mathrm{N}$ also varies across the landscape: with the highest concentrations in the tree plantations and in postdieback Dicranopteris, and relatively low concentrations in the pasture and most of the Metrosideros forest (Plate III). Ground observations revealed that several areas near the forest-pasture boundary with moderately tall canopies and high canopy $\mathrm{N}$ concentrations $(22,34)$ are tree plantations dominated by $\mathrm{N}$-fixing Casuarina equisetifolia $\mathrm{L}$. The wet forest region to the northeast of the focal site includes a finescale matrix of areas with high and low $\mathrm{N}$ concentrations-a surprising result, because high rainfall generally is associated with lower $\mathrm{N}$ concentrations in Hawaiian forests (Schuur and Matson 2001). Following up on these remote observations, we found that the higher $\mathrm{N}$ concentrations reflect in part a greater abundance of the relatively high-N native tree Cheirodendron trigynum (Gaud) A. Heller in the canopy in this region $(51,52)$, as well as open areas in which the $\mathrm{N}$-rich alien herbs Hedychium gardnerianum Sheppard ex Ker Gawl and Tibouchina herbacea (DC) Cogn. are present in the canopy (50).

\section{Kōke'e Landscape (4,100 kyr)}

The Kōke'e area is much older than the other regions on the LSAG, and more of its topography is erosional and depositional (Plate IV). However, there is a well-defined area underlain by a constructional volcanic surface on which the focal site is located. This area has a less-pronounced local drainage network (aside from the large and deep valleys that bound and bisect it) than occurs on the younger Laupāhoehoe and Kohala landscapes, because it is underlain by thick, flatlying caldera-filling deposits of the Olokele Formation (Sherrod et al. 2007), which are more resistant to dissection than most Hawaiian lavas.

Tree heights generally are short across the Kōke'e landscape, on both constructional and erosional/depositional surfaces (Plate IV). Major exceptions to this pattern are a tall Cryptomeria plantation along a stream in the lower-rainfall southern part of the landscape (29), other pockets of planted Crytomeria elsewhere $(14,15)$, and an arc of taller Metrosideros forest $500 \mathrm{~m}$ east of the focal site $(23-25)$. This taller native forest is in a topographic depression and so probably has richer soils than the constructional surface (Porder et al. 2005b); it is also sheltered from strong winds, and trees there persisted through hurricanes that passed over this landscape in 1957, 1982, and 1992. One striking feature of the Kōke'e landscape is an open bog in the northeast (16); this area is covered by sedges and very short $(\sim 0.5 \mathrm{~m})$ Metrosideros, as is much of the Alaka'i Swamp to the east.

The areas of higher canopy $\mathrm{N}$ are generally associated with nonnative species: in the planted Cryptomeria and an area of invasive Morella and Psidium cattleianum Sabine (30, 31) (Plate IV) in the southern part of the area, and in smaller areas associated with Cryptomeria plantings or invasions by $\mathrm{N}$ fixing Acacia melanoxylon R. Br. (5) and Morella faya (13). In addition, ground observations show that a stream valley on the northwestern side of the image is dominated by the high-N invasive herb Hedychium gardnerianum. On the constructional surface, concentrations of $\mathrm{N}$ in Metrosideros generally are low; concentrations are higher in the sheltered, Metrosideros-dominated depression already described. Mats of Dicranopteris fern, which cover large portions of the constructional surface and many slopes to the southwest $(9,20,21,32)$, also have low concentrations of N. Overall, erosion and deposition influence more of the Kōke'e landscape 


\section{Shaded Relief}
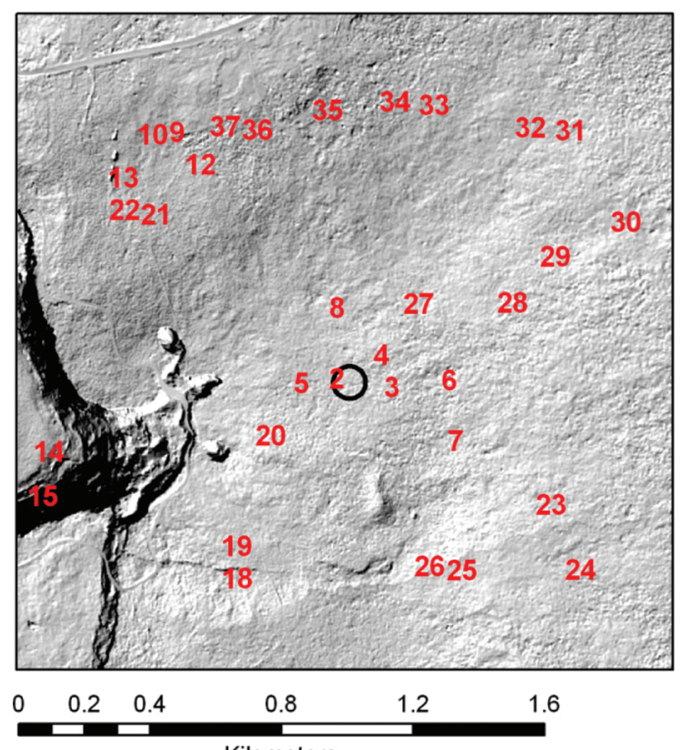

Kilometers

\section{Canopy Nitrogen (\%)}
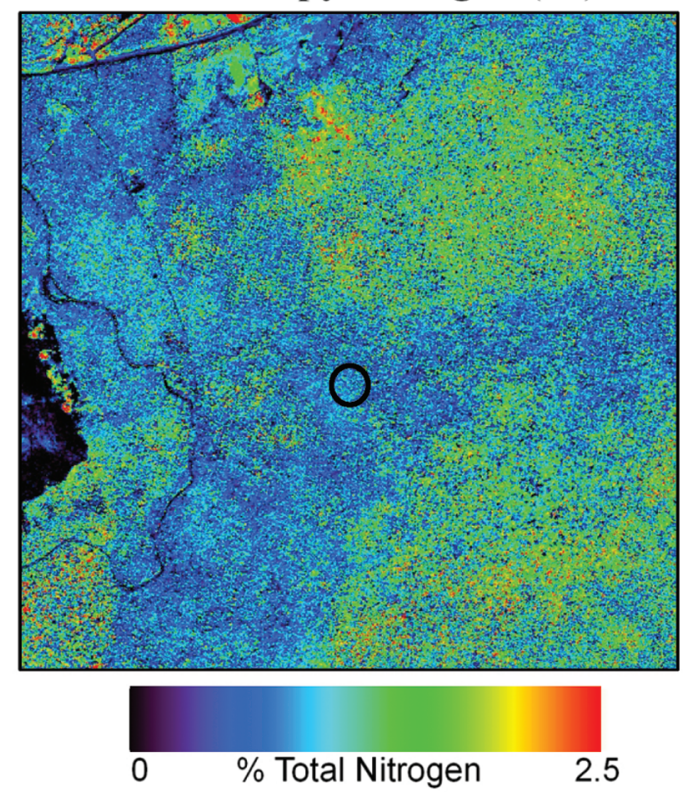

\section{Canopy Height (m)}

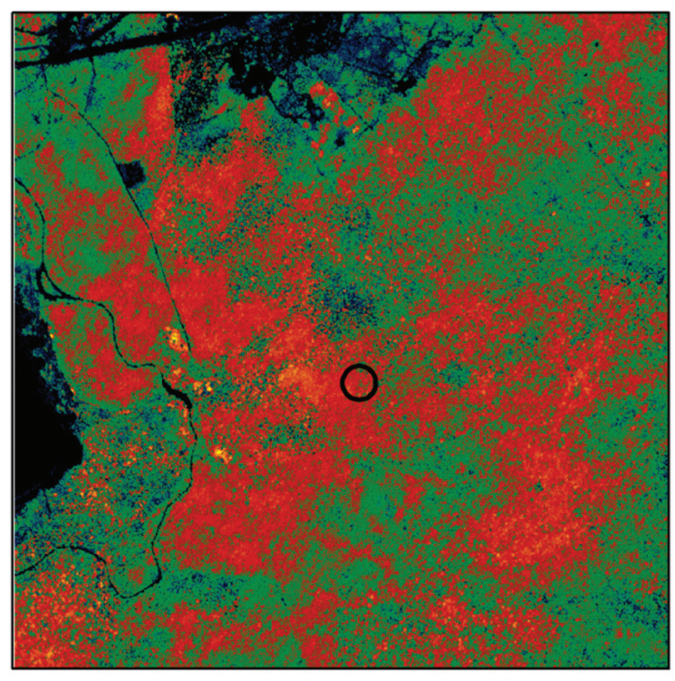

$\mathrm{N}$

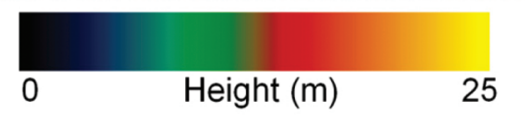

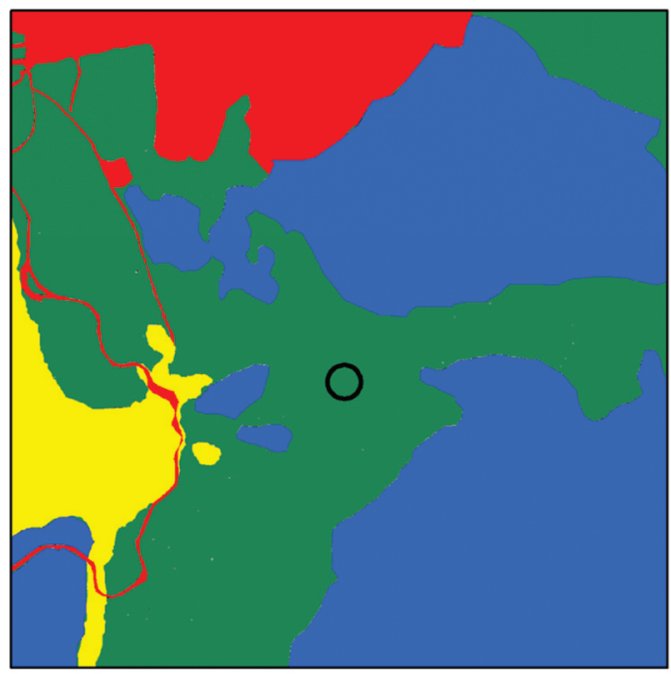

Plate I. Topography and canopy properties in the $2 \mathrm{~km}$ by $2 \mathrm{~km}$ landscape centered on the 300-yr-old Thurston site on a substrate age gradient across the Hawaiian Archipelago. (Upper left) Topography derived from LiDAR. The long-term research site at Thurston is indicated by a circle with $50 \mathrm{~m}$ radius; points where ground-based information on forest structure and composition and canopy photographs were obtained are indicated by numbers. Images that allow zooming in are accessible online at http://www.stanford.edu/group/Vitousek/lsaglandscape.htm. (Upper right) Distribution of canopy heights across the Thurston landscape, also obtained via LiDAR. (Lower left) Nitrogen (N) concentration in the forest canopy, measured with High-Fidelity Imaging Spectrometer (HiFIS). (Lower right) Cover classes in the Thurston landscape, derived from the remote images and ground observations. Dark green represents native-dominated ecosystems on constructional volcanic surfaces; dark blue represents sites with invasive trees (here predominantly the $\mathrm{N}$-fixer Morella faya) at least codominant in the canopy; yellow represents volcanic features, here the wall and floor of Kilauea Iki Crater and some lava-tube skylights; and red represents human-disturbed sites, here active and abandoned pasture in the northern portion of the image and National Park infrastructure (roads and parking lots) elsewhere. This figure is revised and reorganized from Vitousek et al. (2009). 

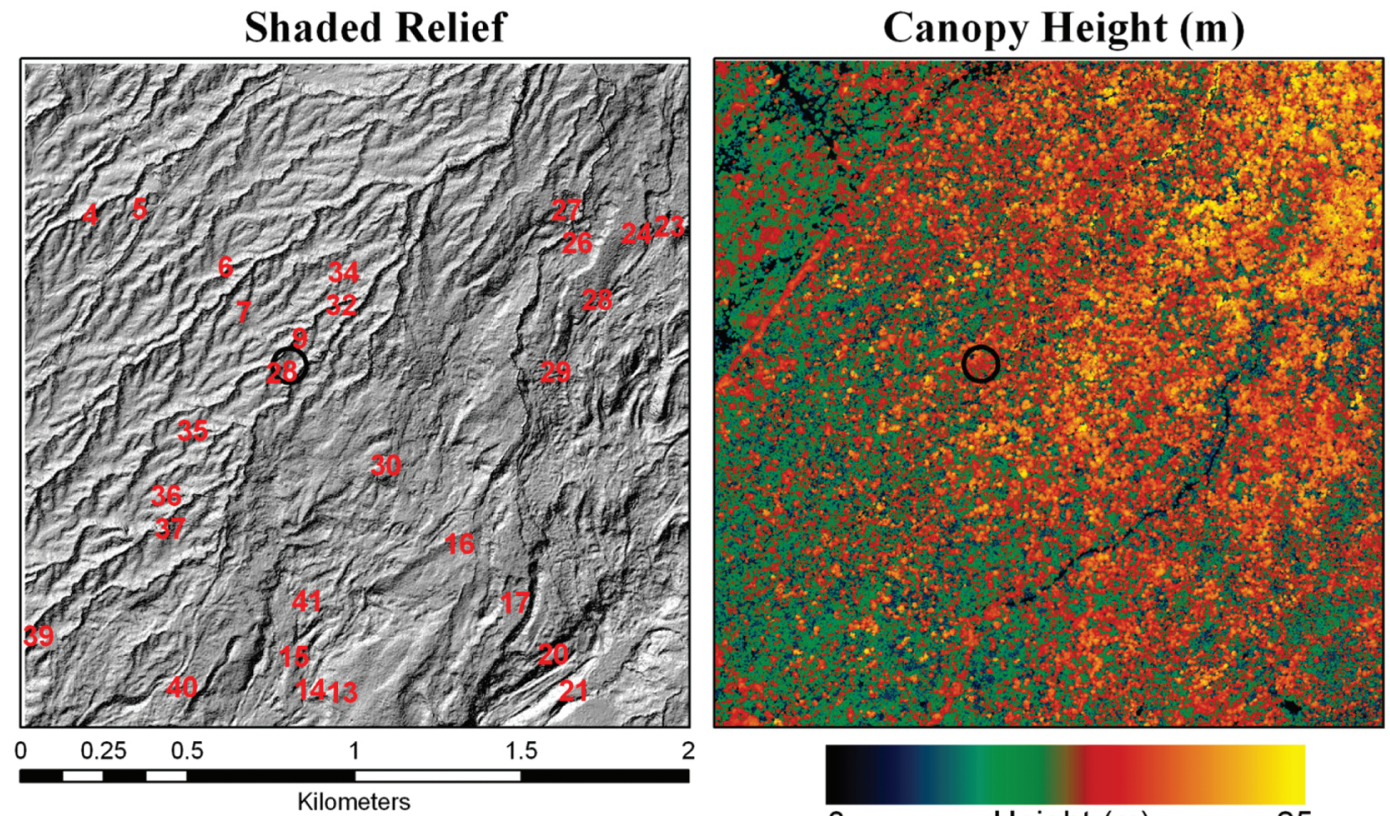

Kilometers

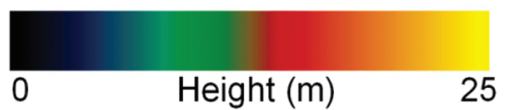

\section{Canopy Nitrogen (\%)}
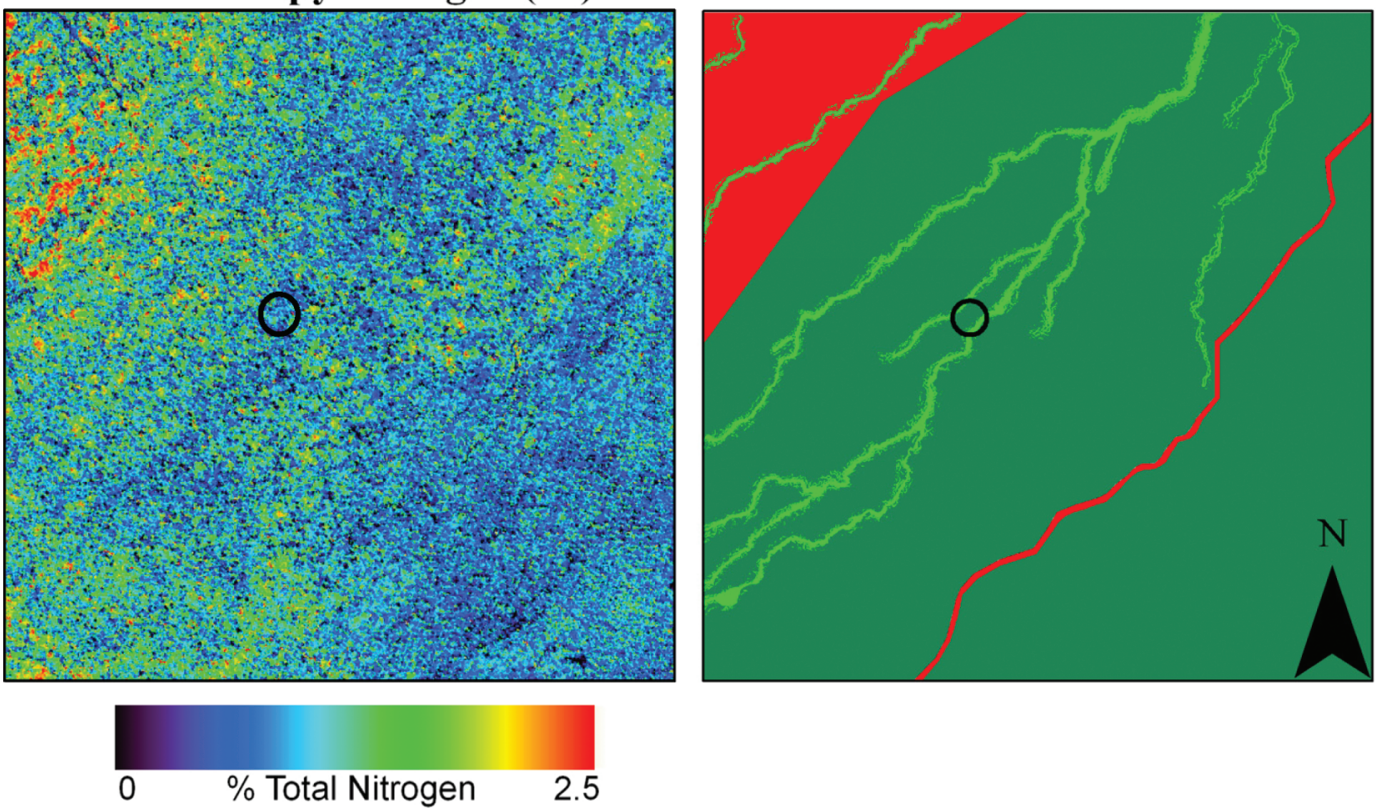

Plate I I. Topography and canopy properties in the $2 \mathrm{~km}$ by $2 \mathrm{~km}$ landscape centered on the 20 kyr Laupāhoehoe landscape, organized as in Plate I. Cover classes include native-dominated ecosystems on constructional surfaces (dark green); eroded areas (light green); and human-disturbed areas (red), here mostly logging of Acacia koa in what was once forested pasture. 


\section{Shaded Relief}

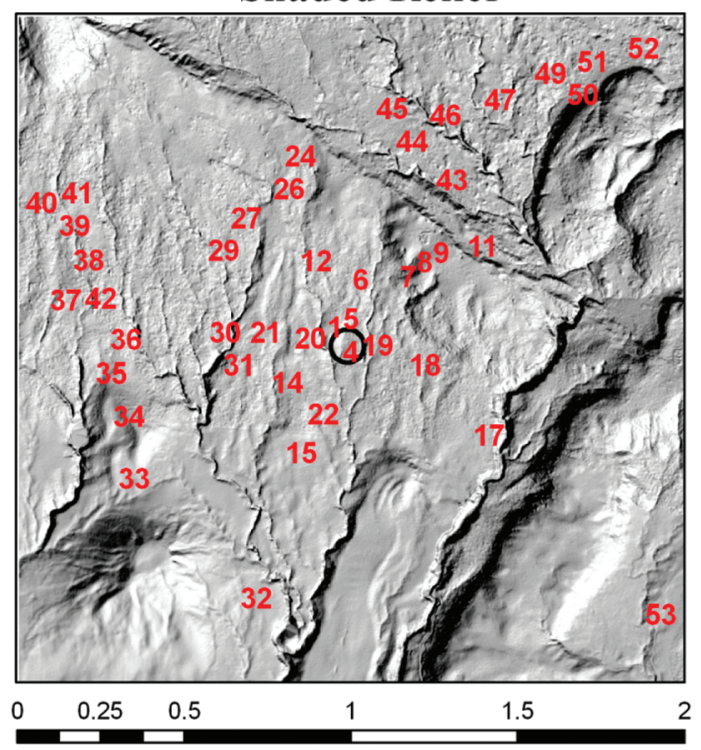

Kilometers

\section{Canopy Nitrogen (\%)}
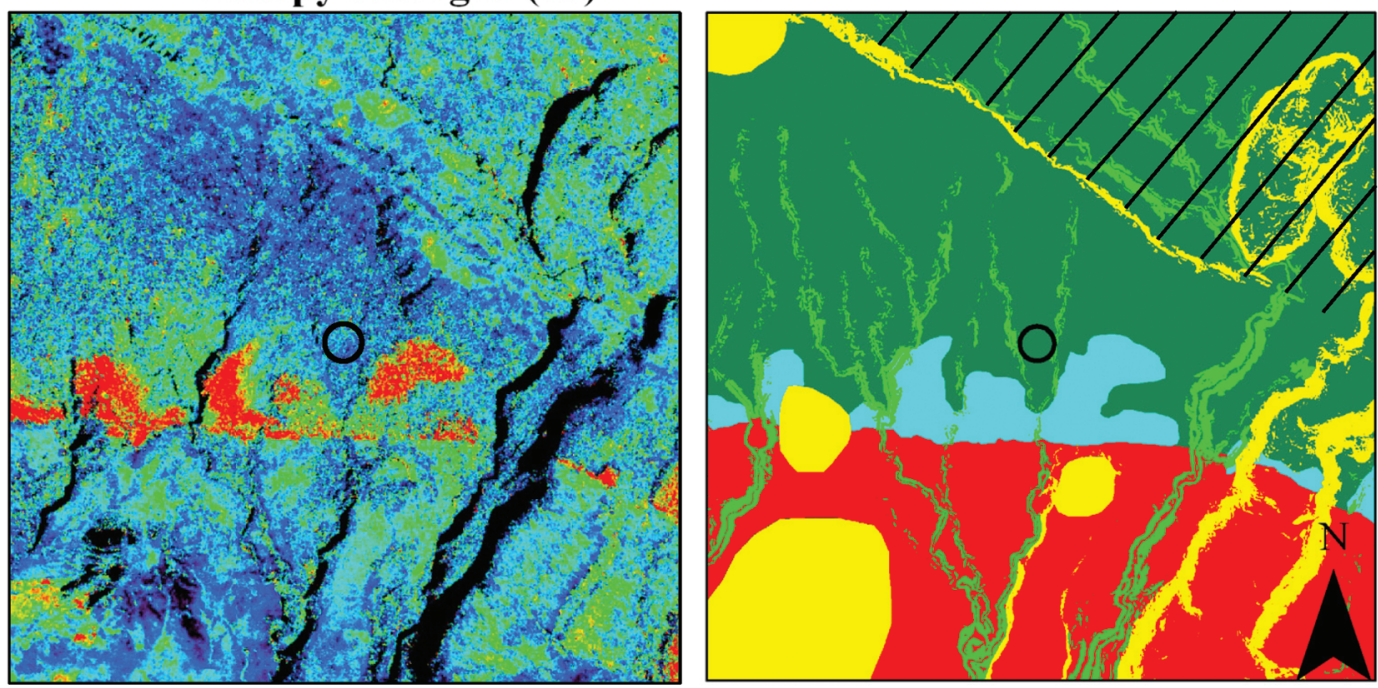

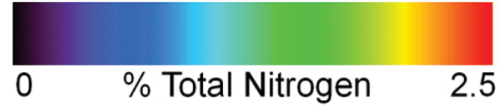

PlATE i i . Topography and canopy properties in the $2 \mathrm{~km}$ by $2 \mathrm{~km}$ landscape centered on the 150 kyr Kohala landscape, organized as in Plate I. Cover classes include native-dominated ecosystems on constructional surfaces (dark green); eroded and depositional areas (light green); volcanic and tectonic features (yellow), here cinder cones, the steep sides of trachyte flows, and a fault scarp; human-disturbed areas (red), here mostly pasture; and plantations of introduced trees (light blue). The hatched area to the northeast receives substantially more rainfall than the remainder of the image, or the other landscapes. 
Shaded Relief

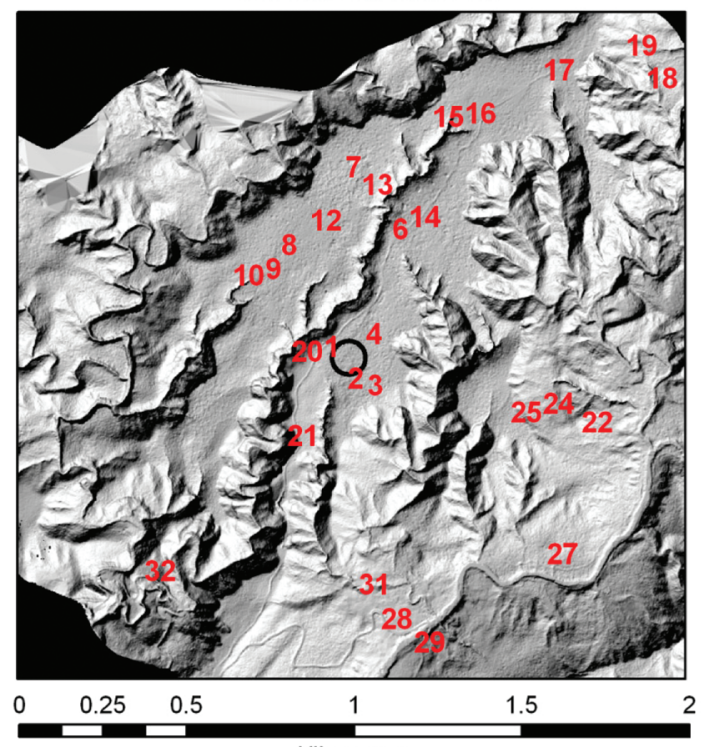

Kilometers

\section{Canopy Nitrogen (\%)}
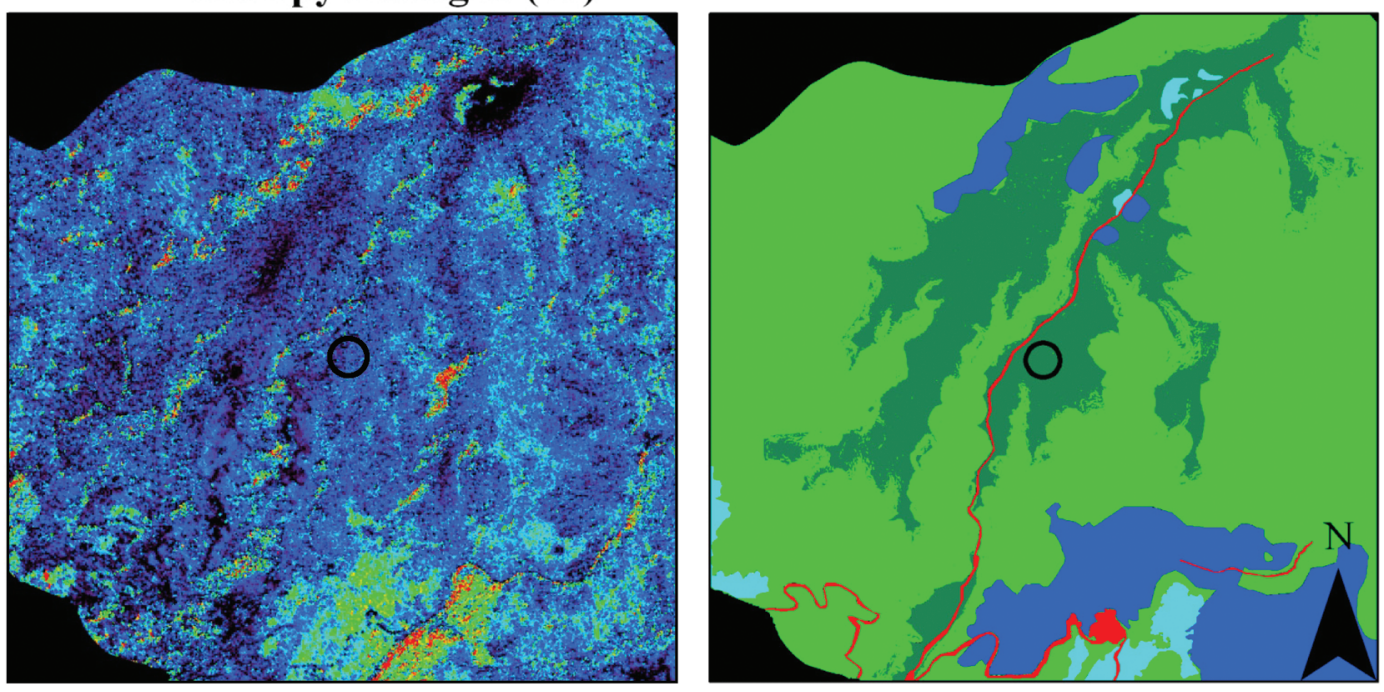

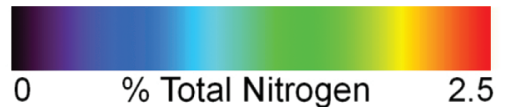

Plate iv. Topography and canopy properties in the $2 \mathrm{~km}$ by $2 \mathrm{~km}$ landscape centered on the 4,100 kyr Kōke'e landscape, organized as in Plate I. Cover classes include native-dominated ecosystems on constructional surfaces (dark green); eroded and depositional areas (light green); invaded areas (dark blue), here mostly Morella faya and Psidium cattleianum, with some Hedychium gardnerianum and Acacia melanoxylon; human-disturbed areas (red), here mostly a road and picnic area; and plantations of introduced trees (light blue). 
than they do in any of the younger ones (Plate IV). Tree plantations and biological invasions also contribute to landscape-level variation in canopy structure and chemistry, particularly on lower slopes and in valley bottoms.

\section{CONCLUSIONS}

Aircraft-based remote sensing can provide highly resolved, synoptic analyses of the topography, canopy heights, and canopy $\mathrm{N}$ concentrations of forested landscapes; especially when supplemented by ground-based observations, they can provide far richer information than can be obtained at comparable spatial scales from ground-based studies alone. These analyses do not depend on either extrapolations of known sites or "ground-truthing" of remotely sensed images; rather they are direct, distributed measurements of ecosystem properties on the landscape scale. Here we used the remote measurements to provide a regional perspective on the results of long-term studies in particular sites; remote observations provide a direct measure of ecosystem properties on the landscape scale as these vary with long-term soil and landscape development. Aircraft-based measurements can also identify and analyze ecosystem dynamics that might be difficult to observe from the ground. Finally, they can be enjoyable, because on-theground measurements designed to pursue the sources of variance detected by airborne remote sensing require that investigators get into every unique portion of a study landscape. In doing so, new features of the landscape, and new biological communities, may be discovered. For example, the Kōke'e treeheight imagery (Plate IV) suggested to us that there might be an incipient bog like that at point 16 developing on an adjacent ridge, in the area near point 9. Ground-based observations showed that this area is not boglike; rather, it is dominated by a Dicranopteris thicket. However, in getting there we found striking "barrens" of sparse Metrosideros canopies over soil surfaces with pedogenic concretions that looked like a rough young ' $a$ ' $\bar{a}$ lava flow at and around point 8 . We had not observed this combination of features previ- ously and now are attempting to understand the factors that brought it into being.

\section{ACKNOWLEDGMENTS}

We thank T. Varga, D. Knapp, T. KennedyBowdoin, R. Martin, M. Jones, M. Eastwood, P. Gardner, S. Lundeen, C. Sarture, and R. Green for airborne data collection and analysis support. Douglas Turner prepared the Web-based supplementary material.

\section{Literature Cited}

Asner, G. P., R. F. Hughes, T. A. Varga, D. E. Knapp, and T. Kennedy-Bowdoin. 2009. Environmental and biotic controls on aboveground biomass throughout a Hawaiian rainforest. Ecosystems 12:261-278.

Asner, G. P., R. F. Hughes, P. M. Vitousek, D. E. Knapp, T. Kennedy-Bowdoin, J. Boardman, R. E. Martin, M. Eastwood, and R. O. Green. 2008. Invasive plants alter 3-D structure of rainforests. Proc. Natl. Acad. Sci. U.S.A. 105:4519-4523.

Asner, G. P., D. E. Knapp, M. O. Jones, T. Kennedy-Bowdoin, R. E. Martin, J. Boardman, and C. B. Field. 2007. Carnegie Airborne Observatory: In-flight fusion of hyperspectral imaging and waveform light detection and ranging (wLiDAR) for three-dimensional studies of ecosystems. J. Appl. Remote Sens. 1: doi: 10.1117/ 1.2794018 .

Asner, G. P., and P. M. Vitousek. 2005. Remote analysis of biological invasion and biogeochemical change. Proc. Natl. Acad. Sci. U.S.A. 102:4383-4386.

Chadwick, O. A., L. Derry, P. M. Vitousek, B. J. Huebert, and L. O. Hedin. 1999. Changing sources of nutrients during four million years of ecosystem development. Nature (Lond.) 397:491-497.

Crews, T. E., K. Kitayama, J. Fownes, D. Herbert, D. Mueller-Dombois, R. H. Riley, and P. M. Vitousek. 1995. Changes in soil phosphorus and ecosystem dynamics across a long soil chronosequence in $\mathrm{Ha}$ wai'i. Ecology 76:1407-1424.

Green, R. O., M. L. Eastwood, C. M. Sarture, T. G. Chrien, M. Aronsson, B. J. 
Chippendale, J. A. Faust, B. E. Pavri, C. J. Chovit, and M. Solis. 1998. Imaging spectroscopy and the Airborne Visible/Infrared Imaging Spectrometer (AVIRIS). Remote Sens. Environ. 65:227-248.

Harrington, R. A., J. H. Fownes, and P. M. Vitousek. 2001. Production and resourceuse efficiencies in N- and P-limited tropical forest ecosystems. Ecosystems 4:646657.

Herbert, D. A., and J. H. Fownes. 1999. Forest productivity and efficiency of resource use across a chronosequence of tropical montane soils. Ecosystems 2:242-254.

Hobbie, S. E., and P. M. Vitousek. 2000. Nutrient limitation of decomposition in $\mathrm{Ha}$ waiian forests. Ecology 81:1867-1877.

Kitayama, K., and D. Mueller-Dombois. 1995. Vegetation changes along gradients of long-term soil development in the $\mathrm{Ha}$ waiian montane rain forest zone. Vegetatio 120:1-20.

Kupiec, J. A., and P. J. Curran. 1995. Decoupling effects of the canopy and foliar biochemicals in AVIRIS spectra. Int. J. Remote Sens. 16:1731-1739.

Lefsky, M. A., W. B. Cohen, G. G. Parker, and D. J. Harding. 2002. Lidar remote sensing for ecosystem studies. BioScience 52:19-30.

Mueller-Dombois, D. 1986. Perspectives for an etiology of stand-level dieback. Annu. Rev. Ecol. Syst. 17:221-243.

Porder, S. J., G. P. Asner, and P. M. Vitousek. 2005a. Ground-based and remotelysensed nutrient availability across a tropical landscape. Proc. Natl. Acad. Sci. U.S.A. 102:10909-10912.

Porder, S. J., A. Paytan, and P. M. Vitousek. 2005b. Erosion and landscape development affect plant nutrient status in the Hawaiian Islands. Oecologia (Berl.) 142:440-449.

Riley, R. H., and P. M. Vitousek. 1995. Nutrient dynamics and trace gas flux during ecosystem development in Hawaiian montane rainforest. Ecology 76:292-304.

Roberts, D. A., M. O. Smith, and J. B. Adams. 1993. Green vegetation, nonphotosynthetic vegetation, and soils in AVIRIS data. Remote Sens. Environ. 44:255-269.

Schuur, E. A. G., and P. A. Matson. 2001.
Aboveground net primary productivity and nutrient cycling across a mesic to wet precipitation gradient in Hawaiian montane forest. Oecologia (Berl.) 128:431442.

Sherrod, D. R., J. M. Sinton, S. E. Watkins, and K. M. Brunt. 2007. Geologic map of the state of Hawai'i. U.S. Geol. Surv. Open File Rep. 2007-1089.

Smith, M.-L., S. V. Ollinger, M. E. Martin, J. D. Aber, R. A. Hallett, and C. L. Goodale. 2002. Direct estimation of aboveground forest productivity through hyperspectral remote sensing of canopy nitrogen. Ecol. Appl. 12:1286-1302.

$\mathrm{Su}, \mathrm{J}$., and E. Bork. 2006. Influence of vegetation, slope and lidar sampling angle on DEM accuracy. Photogram. Engin. Remote Sens. 72:1265-1274.

Ustin, S. L., D. A. Roberts, J. A. Gamon, G. P. Asner, and R. O. Green. 2004. Using imaging spectroscopy to study ecosystem processes and properties. BioScience 54:523-534.

Vitousek, P. M. 2004. Nutrient cycling and limitation: Hawai'i as a model system. Princeton University Press, Princeton, New Jersey.

Vitousek, P. M., G. P. Asner, O. A. Chadwick, and S. C. Hotchkiss. 2009. Landscape-level variation in forest structure and biogeochemistry across a substrate age gradient in Hawai'i. Ecology 90:3074-3086.

Vitousek, P. M., and H. Farrington. 1997. Nutrient limitation and soil development: Experimental test of a biogeochemical theory. Biogeochemistry (Dordr.) 37:6375 .

Vitousek, P. M., D. R. Turner, and K. Kitayama. 1995. Foliar nutrients during long-term soil development in Hawaiian montane rain forest. Ecology 76:712-720.

Wiegand, B. A., O. A. Chadwick, P. M. Vitousek, and J. L. Wooden. 2005. Ca cycling and isotopic fluxes in forested ecosystems in Hawaii. Geophys. Res. Lett. 32:L11404, doi: 10.1029/2005GL022746.

Wolfe, E. W., and J. Morris. 1996. Geologic map of the island of Hawaii. U.S. Geological Survey Map 1-2524-A, Miscellaneous Investigations Series, Reston, Virginia. 